\author{
Ксения И. Стэнпень
}

Вроилавский университет (Врочлав, Польша)

\title{
ОБРАЗНОСТЬ И ЛЕКСИКА КАК ЭЛЕМЕНТЫ ФОРМИРОВАНИЯ ЭКСПРЕССИВНОСТИ ФРАЗЕОЛОГИЧЕСКИХ ЕДИНИЦ
}

Образность является неотъемлемой частью фразеологии. Она определяет фразеологизм как языковую единицу, становясь ее категориальным показателем и характерной чертой. Под образностью понимаем «способность языковых единиц создавать наглядно-чувственные представления о предметах и явлениях действительности» (Мокиенко 1989: 157). Восприятие внеязыковой реальности проецируется в образ, имеющий схожие признаки с предметом или явлением окружающей среды. Структура образа сложна и многоаспектна. Учитывая психологическую природу порождаемого впечатления, необходимо помнить о субъективности формирующегося образа. Но несмотря на огромное влияние индивидуального, неповторимого жизненного опыта на качества отображения окружающей нас действительности, семантическое ядро воображаемого знака с его дистинктивными признаками характерно для мыслительного процесса каждого носителя языка. Импульсом к созданию образа в нашем сознании становятся как натуральные, так и условные знаки. Лексический состав языка является конвенциональным толчком, вызывающим в воображении чувственные переживания. Благодаря характерной для знака коннотации и обогащению ее за счет контекста формирующийся образ становится многогранен и полифоничен. Именно поэтому образность является доминирующим признаком фразеологических единиц - лаконичный код раскрывается многоголосой картиной, не имеющей границ.

Бесспорно, характер передаваемого впечатления кроме символических начертаний может вводить дополнительное эмотивно-выразительное содержание. Отправной точкой становится стилистический регистр словарного состава языка. Выразительные признаки используемой лексики создают определенные смысловые оттенки. Образ таким способом обогащается дополнительными качествами, характер которых имеет непосредственное влияние на формирование экспрессивности и уровня ее усиления. 
Вышеописанная образность становится лишь исходной точкой на пути к количественному определению степени экспрессивности фразеологизмов, под которой понимаем «усиление выразительности, изобразительности, увеличение воздействующей силы сказанного» (Галкина-Федорук 1958: 107). Целью данной работы является анализ сочетания стилистической окраски лексики и особенностей образа, формирующегося на основе конкретных лексических единиц и вводимых ими смысловых оттенков.

Попытка установления степени экспрессивности проводится на мотивированных фразеологизмах, т.к. понимание значения компонентов устойчивого выражения регламентирует его образ (Мокиенко 1989: 161). Проанализированные обороты были выбраны из словаря в случайном порядке, без заданного тематического критерия. Разнообразные типы образа уже были представлены Ш. Балли, С. М. Мезениным, В. М. Мокиенко, В. Н. Телией, Б. Реяковой, С. Скорупкой и др. Нас интересует развитие образа, вызывающее усиление экспрессивности. Если проследим процесс фразеологизации, основанный на переходе свободного словосочетания в устойчивое выражение, то сможем заметить зависимость экспрессивности от характера закрепленного за фразеологизмом образа. Б. А. Ларин в Очерках по фразеологии (1956) описывает этот процесс. В силу частой воспроизводимости свободных оборотов речи постепенно их структура упрощается, значение обобщается, переосмысливается и отрывается от конкретного денотата. Таким образом, наблюдаем процесс семантического обновления, процесс метафоризации - переход прямого значения в переносное (Мокиенко 1989: 162). Мы помним, кроме всего прочего фразеологизм отличается от свободного оборота проявлением у него экспрессивности. Иными словами, если противоречие между прямым и переносным значениями некогда конкретных, осязаемых предметов создает чувстенное переживание, под которым мы понимаем экспрессивность, то увеличение подобного противоречия, как пропасти, в сторону абстрагирования образа повлияет на усиление экспрессивности. Отсюда следует, что вследствие большего ментального усилия из-за отсутствия материального денотата, необходимо совершить дополнительные ассоциативные действия, которым сопутствует также дополнительное чувственное волнение. Значит, абстрактный образ по сравнению с конкретным находится на высшем экспрессивном уровне. Одержать победу проявляет большую экспрессивность, чем заблудиться в трех соснах, альфа и омега экспрессивнее, чем серая мышка.

На диапозон экспрессивности также влияет эмотивный потенциал образной коннотации. Многие исследования идеографических полей языка показали, что тематические группы и семантические поля негативных элементов внеязыковой среды представлены гораздо шире, чем позитивных. Испокон веков такие группы, как лень, трусость, глупость, злость, уродство, болезнь, бедность, смерть и многие др. вызывали огромную вовлеченность 
в процесс языкового творчества, что привело к обогащению лексического состава образными выражениями с характерной эмоциональной выразительностью. Именно поэтому, конкретный и абстрактный образы можем дополнить разделением на эмоциональные оттенки, причем негативная коннотация окажется на более высоком экспрессивном уровне.

Приближаясь к попытке графического представления диапозона экспрессивности, необходимо выбрать единицу меры. Критерием усиления экспрессивности фразеологизмов оказывается рост насыщенности определенных признаков. По предложению Эвы Стрась (Ewy Straś), такой мерой может быть единица интенсивности, т.к. именно интенсивность является количественным проявлением признака (Straś 2008: 21). Для определения шкалы градации признака следует принять нулевой уровень, которым являются неэмоциональные безобразные устойчивые обороты, подвергшиеся дезактуализации, напр., термины жилой дом, скорая помощь, черная дыра, генеральный штаб, гонка вооружений и др., или коллокации - время от времени, как бы там ни было, продолжение следует, по крайней мере, на всякий случай и др. Каждый переход с одного уровня усиления признака на другой соответствует присвоению обороту 1 единицы интенсивности (далее ЕИ). Таким образом, ось координат образа будет представлена пунктами возрастающей экспрессивности: конкретный образ с положительной коннотацией, конкретный образ с негативной коннотацией, абстрактный образ с положительной коннотацией и абстрактный образ с негативной коннотацией (см. рис. 1).

Вторая ось координат представляет собой влияние стилистической окраски лексики на развитие экспрессивности. Лексический пласт языка неоднороден и имеет много вариантов. Если в основу расслоения состава языка положим критерий смыслового и экспрессивно-функционального своеобразия языковых средств, то градация лексики по признаку экспрессивности будет базироваться на функциональных стилях с разделением на позитивный и негативный оттенки. Точкой отсчета станут слова нейтрального и разговорного стиля, десигнаты которых не отличаются стилистической маркированностью. К примеру, такая лексика, как коса, сnать, дуб, время, чтобы, идти, всех, корова, поезд, раздевалка, электричка, пятак и т.д. Но в то же время нейтральная лексика, поставленная в условия определенного контекста, может переосмысливаться. Те же корова или дуб, употребленные по отношению к характеристике человека, приобретают пейоративное значение. Следовательно, нейтральная лексика с негативной коннотацией займет более высокий экспрессивный уровень.

Следующую позицию на оси лексического пласта займет разговорная лексика с разграничением по характеру стилистической окраски: добряк, молодчина, славненький, компанейский, хорошенько, играючи как примеры позитивной оценки и лежебока, бедняга, толкучка, гуляка, недоучка, нытик, 
безалаберный, допотопный, навеселе, ехидничать, прихворнуть - примеры негативной маркированности. Однако сдедует заметить, что разговорная лексика позитивного потенциала слабее по экспрессивности, чем нейтральная - негативной оценки: ср. разг. добряк и нейтр., пренебрежительное циик - 'комическая ситуация', разг. вздремнуть и нейтр., негативное смеяться - 'пренебрегать кем-т., чем-т.', в силу чего нейтральная негативная лексика займет высшее место на оси экспрессивности. Еще большей экспрессивностью отличается лексика высокого стиля, к которому отнесем слова официально-деловой, научной, публицистической и художественно-поэтической речи: претворение, трибуна, избранник, отрада, озарение, соратник, непоколебимьій, величественный, местожительство, впредь, погашать, дискурс, формирование, взаимозависимость - положительной коннотации и хищение, утеря, неплательщчик, воспаление, вульгаризировать, обречь, скорбь, чужбина, как примеры отрицательной эмотивности (Калинин 1966: 154-169). И наконец, наивысшей степенью экспрессивности обладает ненормативная лексика, где интенсивность возрастает от просторечной лексики через жаргон, представленный по нарастающей социолектом, субстандартом, арготизмами, к вульгаризмам. Важным критерием установления степени экспрессивности ненормативного пласта является узнаваемость конкретных единиц носителями языка.

Имея полную расшифровку системы координат, которая представлена видами образа в вертикальном направлении и лексикой функциональных стилей в горизонтальной координате с единицей измерения равной 1 ЕИ, можем проанализировать развитие экспрессивности фразеологических оборотов с опорой на графическое изображение.

Быть на высоте - 'правильно проявить себя'. Быть - нейтр., высота - нейтр., безэмоциональное, безэкспрессивное, т.е. находится на уровне 0 ЕИ. Образ, в свою очередь, не поддается осязаемости из-за своего пространсвенного значения, поэтому он соответствует абстрактному образу +, т.е. с позитивной коннотацией, что дает обороту 3 ЕИ. В сумме фразеологизм получает 3 ЕИ (см. рис. 1).

В глубине души - 'о самых сокровенных переживаниях, мыслях'. Глубина - нейтр., душа - лексема высокого стиля, позитивной окраски (4 ЕИ), метафизической природы, но антропоцентрического плана, что способствует отождествлению с человеческой природой, а тем самым приближает абстрактный образ к мирской жизни, оставляя его, однако, в категории нематериальной. Таким образом, экспрессивность образа имеет 3 ЕИ, а лексического состава - 4 ЕИ, в сумме фразеологизм обладает экспрессивностью в 7 ЕИ. Из чего следует, что данный фразеологизм экспрессивнее приведенного выше.

Всадить нож в спину - 'предательски нанести удар, которого не ждут'. Глагол всадить употреблен в переносном значении - 'поместить во что-нибудь', и дополнительно имеет окраску грубости. Нож - нейтр., но в дан- 
ном обороте получает отрицательную оценку, т.к. ассоциируется с опасностью и болью. Принимаем верхнюю границу лексической экспресссивности - 3 ЕИ. Образ, в свою очередь, представляется конкретным, но с бессомненной негативной маркированностью (2 ЕИ). В итоге экспрессивность находится на уровне 5 ЕИ.

Живого места нет - 'кто-либо сильно изранен, избит'. Живой - нейтр., но имеет положительну оценку (+ 1 ЕИ), место и нет - нейтр., невыразительные лексемы. Образ, содержащийся фразеологизмом, достаточно осязаем и вызывает чувство страха, сочувствия и беспомощности, что влияет на появление негативной коннотации (+2 ЕИ). Общий уровень экспрессивности оборота составляет 3 ЕИ, что указывает на идентичность с фразеологизмом в глубине души.

Наступать на грабли - 'сделать так, что последствия дадут о себе знать'. Слова относятся к нейтральному стилю, поэтому не отличаются выразительностью. В то же время, конкретный образ передает полную гамму чувств, которые можно испытать в данной ситуации. В результате, фразеологизм отличается экспрессивностью на уровне 2 ЕИ.

Tpenamь языком - 'слишком много говорить, говорить вздор'. Tpenams - просторечное слово (6 ЕИ). Язык в данном случае является нейтральной лексемой. Образ, в свою очередь, достаточно наглядный, однако обладает отрицательной коннотацией (2 ЕИ). Фразеологизм характеризуется экспрессивностью на уровне 8 ЕИ.

Базарная баба - 'грубый, вульгарный, крикливый человек'. Базарный - разговорное прилагательное, имеющее значение 'непристойный, площадной’, т.е. с негативной окраской; баба - разг, с отрицательной маркированностью (3 ЕИ). Образ, закрепленный за оборотом, конкретный и негативный (2 ЕИ). Общая сумма - 5 ЕИ, что соответствует экспрессивности фразеологизма всадить нож в спину.

Льбу давить - 'с пренебрежением об улыбающимся'. Льљба - арготизм от улыбка, давить - перен., жаргонное ‘форсировать что-либо’ (7 ЕИ). Образ принудительной, неестественной улыбки, напоминающий гримасу, конкретен, но негативен (2 ЕИ). Степень экспрессивности достигает уровня 9 ЕИ.

Сучья зона - 'зона, где управляют заключенные, пошедшие на союз с администрацией’. Сучья в данном обороте является арготизмом, а зона - разг. с отрицательной коннотацией (7 ЕИ). Образ характеризуется пространственностью и абстрагируется в силу жаргонного компонента (4 ЕИ). При таких условиях данный фразиологизм получает 11 ЕИ.

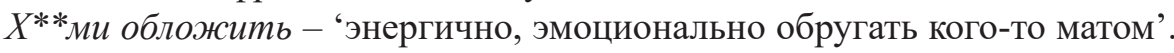
Обложить в переносном значении 'выругать кого-то нецензурными словами' является разговорным с негативной окраской, второй компонент относится к пейоративным вульгаризмам (8 ЕИ). Образ представляется абсурдальным и низменным, поэтому в общей сложности фразиологизм с 12 ЕИ является самым экспрессивным из всех приведенных ранее. 


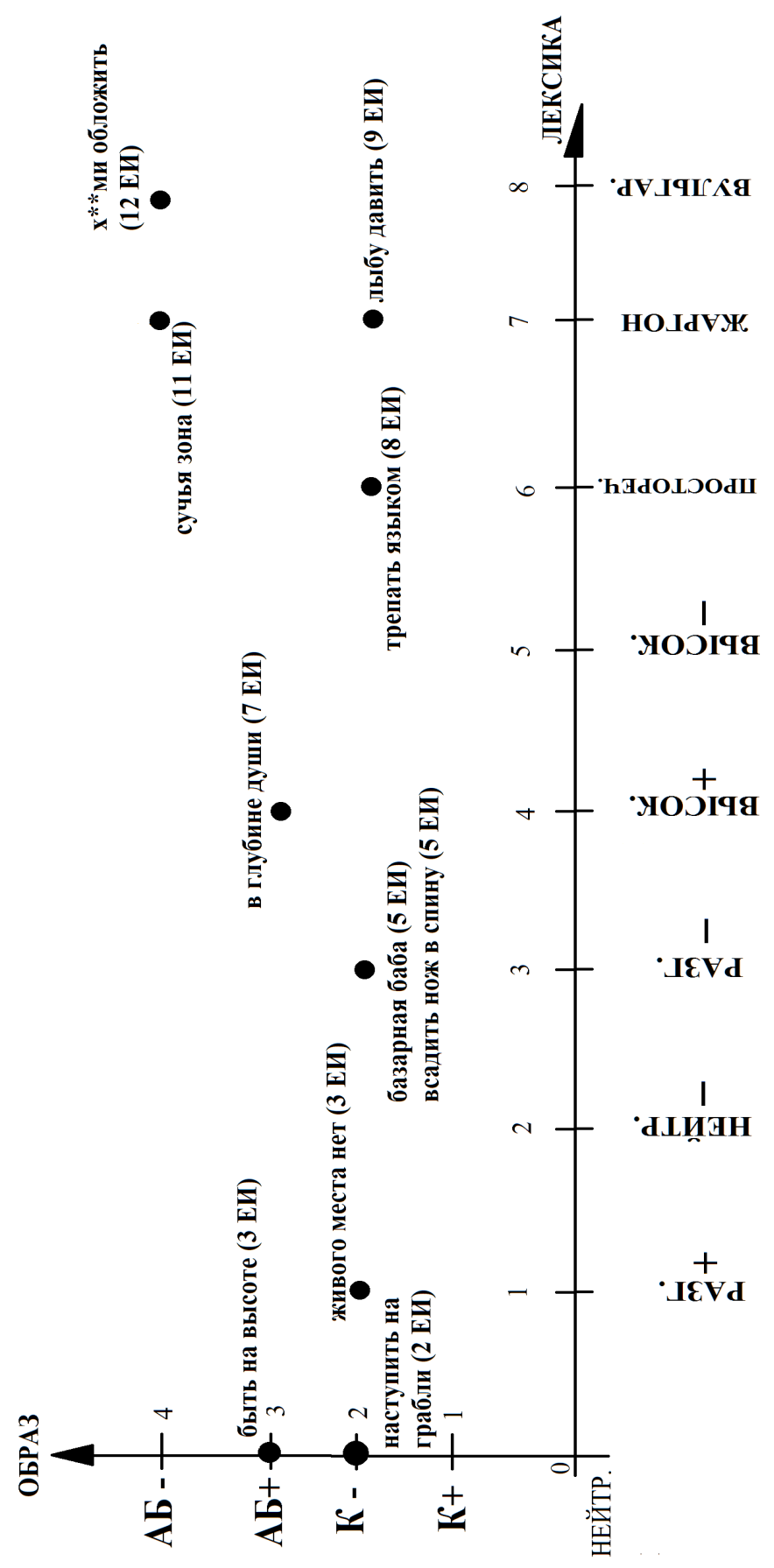

פ 
Так, как было отмечено ранее, данный анализ является попыткой охарактеризовать рост экспрессивности через образ, закрепленный за фразеологизмами, и лексический пласт языка, используя при этом количественные показатели. В дальнейшем необходимо также определить, насколько возрастает интенсивность экспрессии при наличии в составе оборота глаголов, обозначающих активное, динамическое действие; каков количественный рост ЕИ при появлении неологизмов в устойчивых оборотах, являющихся трансформациями. Вдобавок анализу должен быть поддан семантический пласт языка в сочетании с формирующимся образом.

В перспективе определение диапазона экспрессивности фразеологических единиц позволит конкретизировать их принадлежность к определенному функциональному стилю в синхроническом плане. В свою очередь, стилистическая дифференциация послужит дополнению структуры словарных помет и корректному использованию фразеологизмов в дидактике.

\section{Библиография}

Галкина-Федорук Е. М. (1958), Об экспрессивности и эмоциональности в языке, [в:] «Сборник статей по языкознанию», Москва, с. 103-124.

Гвоздарев Ю. А. (1988), Рассказы о русской фразеологии, Москва.

Калинин А. В. (1966), Лексика русского языка, Москва.

Краткий словарь блатного жаргона, http://www.aferizm.ru/jargon/slovar.htm [dostęp: 27.05.2017]. Ларионова Ю. А. (2014), Фразеологический словарь современного русского языка, Москва.

Мезенин С. М. (1983), Образность как лингвистическая категория, «Вопросы языкознания 6», Москва, с. 48-57.

Мелерович А. М., Мокиенко В. М. (2008), Семантическая структура фразеологических единии современного русского языка, Кострома.

Мокиенко В. М. (1989), Славянская фразеология, Москва.

Словари и энциклопедии на Академике, http://dic.academic.ru/ [dostęp: 27.05.2017].

Chlebda W. (2003), Elementy frazematyki. Wprowadzenie do frazeologii nadawcy, Łask.

Skubalanka T. (1972), O ekspresywności języka, „Annales Universitatis Mariae Curie-Skłodowska”, vol. XXVII, 8, Lublin: Polonia, s. 123-135.

Straś E. (2008), Kategoria intensywności we frazeologii języka polskiego i rosyjskiego, Katowice. 


\title{
IMAGING AND LEXIS AS THE ELEMENTS SHAPING THE EXPRESIVENESS OF PHRASEMES
}

\author{
(Summary)
}

\begin{abstract}
Imaging is a feature determining phrasemes. The nature of images contained in phrasemes is characterised by multi-dimensionality as images are comprised of general features of items and individual observations. As a result, image treatment might be perceived as subjective and doubtful from the point of view of a reliable expressiveness determinant. However, attention is paid to the generally accepted and understood perception of the non-verbal world, i.e. the relevant features of the denotation. It comprises the basis of the internal form of phrasemes. Its literalness or irrationality affects the shaping of expressiveness, and the reality or abstraction of an image determines the level of expressiveness intensity. Phrasemes randomly selected for examination demonstrated that the qualities of vocabulary contained in them also influence the intensity of expressiveness. Furthermore, a combination of a characteristic image with marked vocabulary strengthens the level of expressiveness. The described process was presented in a quantitative manner, the measurement unit of which is the unit of intensiveness (UI). An attempt to compare the expressiveness of selected phrasemes was made on the basis of the UI indicator.
\end{abstract}

Keywords: imaging, markedness, lexis, expressiveness, phraseme, intensiveness

\section{OBRAZOWOŚĆ I LEKSYKA JAKO ELEMENTY KSZTALTOWANIA EKSPRESYWNOŚCI FRAZEOLOGIZMÓW}

(Streszczenie)

Determinującą cechą związków frazeologicznych jest obrazowość. Natura obrazu, zawartego w frazeologizmach, charakteryzuje się wieloaspektowością, ponieważ nakładają się na niego ogólne właściwości przedmiotów oraz indywidualne spostrzeżenia. W wyniku czego traktowanie obrazu może być rozumiane jako subiektywne i wątpliwe pod względem wiarygodnego determinanta ekspresywności. Natomiast zwracana jest uwaga na ogólnie przyjęty i rozumiany odbiór świata pozajęzykowego, czyli relewantne cechy denotatu. One właśnie stanowią podstawę formy wewnętrznej frazeologizmów. Jej dosłowność albo irracjonalność wpływa na kształtowanie ekspresywności, jak również rzeczywistość bądź abstrakcyjność obrazu określa stopień nasilenia ekspresji. Losowo wybrane do zbadania frazeologizmy wykazały, że walory słownictwa zawartego w ich składzie też oddziałują na intensywność ekspresywności. Ponadto połączenie charakterystycznego obrazu z nacechowanym słownictwem wzmacnia poziom ekspresji. Opisany proces został przedstawiony w sposób ilościowy, którego jednostką miary stanowi jednostka intensywności (JI). Na podstawie wskaźnika JI podejmuje się próba porównania ekspresywności wybranych związków frazeologicznych.

Słowa kluczowe: obrazowość, nacechowanie, leksyka, ekspresywność, frazeologizm, intensywność 